\title{
Pharmaceutical Resources
}

National Cancer Institute

\section{Source}

National Cancer Institute. Pharmaceutical Resources. NCI Thesaurus. Code C15834.

A collection of pharmaceutical substances available for research use 